\title{
Celebrando 20 anos da Revista Contexto \& Saúde
}

\author{
Thiago Gomes Heck ${ }^{1}$
}

Nesta edição, publicada no último trimestre de 2021, a Revista Contexto \& Saúde (RCS) comemora seus 20 anos de divulgação científica com 32 artigos publicados em uma edição extra. Estes trabalhos estão organizados nas seções da revista nas seguintes áreas editoriais: Ciências Farmacêuticas \& Saúde $(n=6)$, Nutrição \& Saúde $(n=5)$, Fisioterapia \& Saúde $(n=5)$, Educação \& Saúde $(n=4)$, Exercício Físico \& Saúde $(n=3)$, Enfermagem e Suas Contribuições para a Prática $(n=3)$ e também artigos em temáticas gerais $(n=6)$. Temos a satisfação de celebrar a data, oportunizando a publicação dos artigos de autores de 11 diferentes Estados brasileiros, divulgando o conhecimento produzido em 35 instituições de ensino. Assim, mantendo a RCS ativa e em evolução, comemoramos o aniversário da Revista com a certeza do reconhecimento em abrangência nacional, e iniciando uma caminhada na internacionalização, mas fundamentalmente agradecendo aos autores e revisores que atuaram nestas duas décadas em prol da educação e da divulgação científica, assim como agradecemos à equipe técnica da Editora Unijuí pelo empenho e dedicação nos processos editoriais. Destacamos também o intenso trabalho dos professores da Unijuí, pesquisadores do Programa de Pós-Graduação em Atenção Integral à Saúde pela atuação como editores das seções (áreas) da RCS, responsáveis pelo fluxo avaliativo de mais de 300 artigos submetidos por ano.

$\mathrm{Na}$ edição atual, entre os artigos publicados, um estudo caracterizou o uso de medicamentos por estudantes de Ensino Médio do Rio de Janeiro, ${ }^{1}$ outro abordou o processo formativo do estudante de Farmácia, ${ }^{2}$ e outro avaliou a estabilidade de formulações farmacêuticas, ${ }^{3}$ demonstrando a diversidade de estudos dentro do mesmo campo do conhecimento. Esta área editorial atual de nossa Revista dialoga com o volume 10, n 18 de 2010 da RCS, que debatia o uso racional de medicamentos, ${ }^{4-5}$ característica marcante do curso de Graduação de Farmácia da Unijuí ao longo dos anos, e representa o trabalho realizado pela editora-chefe da RCS por aproximadamente uma década, a professora Marilei Uécker Pletsch. Já para a edição de 2013 tive a difícil tarefa de assumir a editoração da revista em substituição à professora Marilei, que permaneceu atuando como editora na seção Ciências Farmacêuticas da RCS, e claro, auxiliando este editor iniciante no processo de editoração.

$\mathrm{Na}$ área da Nutrição, os estudos atuais exploram o impacto dos alimentos ultraprocessados no perfil biométrico de escolares do sul de Minas Gerais, ${ }^{6}$ e também os fatores

\footnotetext{
${ }^{1}$ Grupo de Pesquisa em Fisiologia - GPeF. Programa de Pós-Graduação em Atenção Integral à Saúde. Programa de Pós-Graduação em Modelagem Matemática e Computacional. Universidade Regional do Noroeste do Estado do Rio Grande do Sul - Unijuí. https://orcid.org/0000-0002-1242-5423
} 
associados à qualidade de vida de idosos. ${ }^{7}$ A presença do campo da Nutrição na RCS, especificamente em estudos dos hábitos alimentares de escolares, marca, portanto, presença atualmente e no histórico da Revista, como pode ser vista no segundo número da RCS no estudo sobre o consumo de erva-mate em escolares de ljuí, ${ }^{8}$ cidade-sede da Editora Unijuí, que abriga por 20 anos esta Revista com muita dedicação e cuidado. E como parte do Conselho de Redação da Editora Unijuí, desde a primeira edição da RCS, a professora Maristela Borin Busnello participou do início da criação da Revista, e até os dias atuais segue contribuindo como autora e revisora deste periódico.

Na seção Fisioterapia, a edição atual traz um ensaio clínico randomizado com 18 adultos sobre a redução de gordura abdominal, ${ }^{9} \mathrm{e}$ a avaliação da postura e equilíbrio de 33 idosos após a realização de pilates. ${ }^{10}$ Nas últimas edições a RCS tem publicado estudos sobre o impacto da obesidade e sobrepeso na capacidade funcional, ${ }^{11}$ assim como estudos de avaliação funcional de idosos em diferentes condições. ${ }^{12}$ Ainda, com diálogo direto entre as seções da RCS, os trabalhos sobre sedentarismo e atividade física da área editorial "Exercício Físico \& Saúde" trazem o impacto do sedentarismo em comorbidades relacionadas ao diabetes e obesidade. ${ }^{13-14}$

A área de Enfermagem, sempre presente na RCS, fecha o ano de 2021 com trabalhos sobre depressão e ansiedade, ${ }^{15}$ apoio social para portadores de necessidades especiais ${ }^{16}$ e textos que avaliam a qualidade de vida de pacientes em atendimento ambulatorial. ${ }^{17}$ Também característico do curso de Enfermagem da Unijuí, a edição atual e, por exemplo, a segunda edição da RCS, tem nas entrelinhas a temática da preocupação com o cuidado das pessoas e a avaliação dos serviços, como nos textos "Defrontando-se com a dor do outro - experiências de alunos iniciantes em enfermagem" e "Cuidados de Enfermagem a clientes em uso de catéteres curtos de infusão", de 2002. ${ }^{18-19}$ Sendo a Enfermagem uma das áreas com maior número de submissões de artigos anualmente, naturalmente em 2019 a então editora da seção, professora Adriane Cristina Bernat Kolankiewicz, assume como editora-chefe da RCS, mantendo não somente a área da Enfermagem, mas toda a revista em pleno funcionamento.

A pluralidade da RCS e o incentivo ao diálogo interdisciplinar é explícito na seção "Contexto \& Saúde Geral" com trabalhos sobre a poluição ambiental, ${ }^{20-21}$ assim como na seção "Educação \& Saúde" com os trabalhos sobre a educação em saúde da atenção primária brasileira no contexto da pandemia da Covid-19. ${ }^{22}$ A abordagem sobre a Covid-19 na RCS demonstra também o compromisso com a atualidade no debate científico e na formação de recursos humanos, representando um campo que ainda tem muitos trabalhos em avaliação e que devem ser publicados nas próximas edições da Revista.

Não podíamos deixar de destacar os artigos mais citados nos últimos cinco anos da RCS: o artigo "Fatores de risco para tentativa de suicídio: produção de conhecimento no Brasil", de autoria de Tamires Alexandre Félix, da Universidade Estadual Vale do Acaraú, atualmente conta com 35 citações. ${ }^{23} \mathrm{O}$ trabalho aborda os fatores de risco para a tentativa de suicídio revisando as produções publicadas no Brasil em dez anos, identificando prevalência maior em mulheres, jovens, que vivem sozinhos, desempregados e indivíduos com baixa escolaridade, cená-

Editora Unijuí - Revista Contexto \& Saúde - ISSN 2176-7114 - v. 21, n. 44, out./dez. 2021 
rio fortemente relacionado a um contexto psicossocial de adoecimento e ao uso de drogas psicoativas. Com 25 citações cada, os estudos "A visão do idoso sobre o seu processo de envelhecimento" 24 e "Prevalência de enteroparasitoses em crianças de creches do município de Santo Ângelo, RS" 25 fecham a categoria dos TOP3 artigos em termos de citações. Os artigos mais citados podem ser vistos no link https://scholar.google.com/citations?hl=pt-BR\&view_op=list_hcore\&venue $=$ Ez7rXcUSTyYJ.2021.

Seguimos em busca de progressivas qualificações e adequações para a RCS, ${ }^{26-27}$ assim como todos os editores fizeram com sucesso em seus respectivos tempos. Este processo contínuo e de múltiplas mãos culmina na atual abrangência territorial de autores, leitores, avaliadores e corpo editorial atual da RCS. Nas próximas edições buscamos a celeridade do processo avaliativo e de publicação, sem diminuir a qualidade no processo de avaliação e de editoração, em respeito aos 803 artigos publicados ao longo destes 20 anos de história. Certamente este texto não contemplou todas as pessoas responsáveis pela Revista, mas apenas até onde minha memória permite e minha experiência nesta década na Unijuí e oito anos como editor torna possível. Assim, todos os responsáveis pela RCS ao longo dos tempos, por favor sintam-se homenageados nesta celebração de 20 anos da RCS!

\section{AGRADECIMENTOS}

Agradeço a todos os funcionários da Editora Unijuí pela manutenção da RCS ao longo dos tempos, assim como todos os editores, autores e revisores da revista. Aos professores, alunos e secretário (Giovano Buratti), com vínculo no Programa de Pós-Graduação em Atenção Integral à Saúde que são responsáveis por diversas etapas acadêmicas e administrativas da RCS. Também agradeço às professoras Adriane C. B. Kolankiewicz, Maristela B. Busnello e Marilei U. Pletsch pela troca de ideias e informações na construção deste texto.

\section{REFERÊNCIAS}

${ }^{1}$ Ramos TB, Castilho SR de. Perfil do uso de medicamentos entre estudantes do Ensino Médio de uma escola pública do Rio de Janeiro. Contexto \& Saúde. 2021;21(44). Disponível em: https://www.revistas.unijui.edu.br/index.php/contextoesaude/article/ view/10950

2 Da Silva TS, Farias C de S, dos Santos FF, da Silva Neto IF, Marques AEF. Percepção dos acadêmicos de farmácia sobre a atuação do farmacêutico nas práticas integrativas e complementares em saúde. Rev. Cont. Saúde [Internet]. [citado 29 out. 2021];21(44). Disponível em: https://www.revistas.unijui.edu.br/index.php/contextoesaude/article/ view/11956

${ }^{3}$ Schettert Kerschmer K, Batu de Souza E, Kessler Nunes Deuschle VC. Estabilidade e fotoproteção de formulações contendo extrato de Punica granatum e metoxinamato de octila. Rev. Cont. Saúde [Internet]. [citado 29 out. 2021];21(44). Disponível em: https:// www.revistas.unijui.edu.br/index.php/contextoesaude/article/view/12000

${ }^{4}$ Oliveira KR de, Munaretto P. Uso racional de antibióticos: responsabilidade de prescritores, usuários e dispensadores. Rev. Cont. Saúde [Internet]. 13 jun. 2013. [citado 30 nov. 2021];10(18):43-51. Disponível em: https://www.revistas.unijui.edu.br/index.php/ contextoesaude/article/view/1470 
${ }^{5}$ Foellmer L, Oliveira KR de, Moreira AC. Uso racional de medicamentos: prioridade para a promoção da saúde. Rev. Cont. Saúde [Internet]. 13 jun. 2013 [citado 30 nov. 2021];10(18):53-62. Disponível em: https://www.revistas.unijui.edu.br/index.php/contextoesaude/article/view/1471

${ }^{6}$ Souza e Silva TG de, Bellizze MEP, da Silva MF, Bastos Marques DV, Dias TG, Toloni MH de A, Pereira de Brito TR, Fernandes GR, Lima DB. Perfil antropométrico de alimentos ultraprocessados de escolares de um município mineiro. Rev. Cont. Saúde [Internet]. [citado 29 out. 2021];21(44). Disponível em: https://www.revistas.unijui.edu.br/index. php/contextoesaude/article/view/9607

7 Terra Marinho JR, Manochio Pina MG, Ramos SB. Fatores associados à qualidade de vida, estado nutricional e políticas públicas dos idosos: revisão integrativa. Rev. Cont. Saúde [Internet]. [citado 29 out. 2021];21(44). Disponível em: https://www.revistas. unijui.edu.br/index.php/contextoesaude/article/view/10412

${ }^{8}$ De Negri ST, Fiad AL do A. Consumo da erva-mate, no chimarrão, por escolares das séries iniciais do Ensino Fundamental de escolas públicas do município de ljuí-RS. Rev. Cont. Saúde [Internet]. 2:115-24. Disponível em: https://www.revistas.unijui.edu.br/ index.php/contextoesaude/article/view/1255

${ }^{9}$ Nogueira AM, de Almeida NS, Bonato GSL, da Costa AL, Costa MM, de Araujo BCG, Toledo ACCG. Redução da gordura abdominal localizada em homens através da aplicação pulsada e contínua de terapia combinada associada ao uso da corrente excitomotora de média frequência: ensaio clínico randomizado. Rev. Cont. Saúde [Internet]. [citado 29 out. 2021];21(44). Disponível em: https://www.revistas.unijui.edu.br/index.php/ contextoesaude/article/view/11721

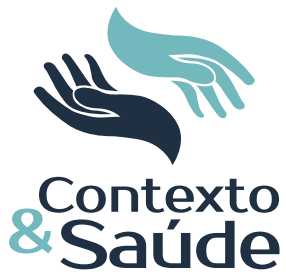

${ }^{10}$ Iop Tavares D, Bordin Viera Schlemmer G, Daros dos Santos T, dos Santos Machado A, Barbosa da Silva J, Medeiros Braz M, Pinheiro Vendrusculo A. Correlação entre equilíbrio postural e força de preensão manual em idosas após pilates na água. Rev. Cont. Saúde [Internet]. [citado 29 out. 2021];21(44). Disponível em: https://www.revistas. unijui.edu.br/index.php/contextoesaude/article/view/11748

${ }^{11}$ Mohr F, Winkelmann ER. Influência de sobrepeso e obesidade na capacidade funcional submáxima em indivíduos com diabetes tipo 2. Rev. Cont. Saúde [Internet]. 7 jun. 2013 [citado 30 nov. 2021];11(21):42. Disponível em: https://www.revistas.unijui.edu.br/index.php/contextoesaude/article/view/402

${ }^{12}$ Martel MRF, Flora GD, Lini EV. Avaliação da capacidade funcional de idosos institucionalizados em um município de pequeno porte do Noroeste do Estado do Rio Grande do Sul. Rev. Cont. Saúde [Internet]. 20 dez. 2018 [citado 30 nov. 2021];18(35):13-8. Disponível em: https://www.revistas.unijui.edu.br/index.php/contextoesaude/article/ view/6835

${ }^{13}$ Quedas CLR, Famá D'Antino ME, R. Quintas RH, Cymrot R, Rocha MM, Blascovi-Assis SM. Adaptação transcultural do MABC-2 e avaliação de crianças de 7 a 11 anos com transtorno do espectro autista. Rev. Cont. Saúde [Internet]. [citado 29 out. 2021];21(44). Disponível em: https://www.revistas.unijui.edu.br/index.php/contextoesaude/article/ view/11833

${ }^{14}$ Rodrigues B da S, Kupske JW, Rasia RF, Dutra TS, Krug MM, Moreira PR, Keller KD, Krug $R$ de $R$. Efeitos do exercício físico na qualidade de vida e aptidão física de pacientes em hemodiálise. Rev. Cont. Saúde [Internet]. [citado 29 out. 2021];21(44). Disponível em: https://www.revistas.unijui.edu.br/index.php/contextoesaude/article/view/11936

${ }^{15}$ Azevedo Minhaqui Ferreira M, Patrício ACF de A, Silva IB do N, Rodrigues BFL, Brasil MHF, Nascimento JA, da Silva RAR. Depressão e ansiedade de pessoas vivendo com HIV/aids. Rev. Cont. Saúde [Internet]. [citado 29 out. 2021];21(44). Disponível em: https://www.revistas.unijui.edu.br/index.php/contextoesaude/article/view/9528

${ }^{16}$ Silveira, A. da, Jantsch, L. B., Fontana, D. G. R., \& da Silva, E. B. Apoio social à população pediátrica e adulta com deficiência residente em contexto rural. Revista Contexto \& Saúde. 2021;21(44). Disponível em: https://www.revistas.unijui.edu.br/index.php/contextoesaude/article/view/11477 
${ }^{17}$ Costa Barbosa JC, Sales AE, Forones NM, Lopes De Domenico EB. Dor crônica e qualidade de vida de pacientes com cânceres gastrointestinais em atendimento ambulatorial. Rev. Cont. Saúde [Internet]. [citado 29 out. 2021];21(44). Disponível em: https://www. revistas.unijui.edu.br/index.php/contextoesaude/article/view/9874

${ }^{18}$ Sartori GS, Rocha MS da, Perlini NMOG. Defrontando-se com a dor do outro - experiências de alunos iniciantes em enfermagem. Rev. Cont. Saúde [Internet]. 27 maio 2013 [citado 30 nov. 2021];2(02):31-44. Disponível em: https://www.revistas.unijui. edu.br/index.php/contextoesaude/article/view/1250

${ }^{19}$ Silva LAA da, Bavaresco E. Cuidados de enfermagem a clientes em uso de catéteres curtos de infusão intravenosa. Rev. Cont. Saúde [Internet]. 27 maio 2013 [citado 30 nov. 2021];2(02):83-99. Disponível em: https://www.revistas.unijui.edu.br/index.php/ contextoesaude/article/view/1253

${ }^{20}$ Silva DCP, Melo C dos S, Oliveira AB de, Pinto LC, Santos NMM dos. Derramamento de óleo no mar e implicações tóxicas da exposição aos compostos químicos do petróleo. Rev. Cont. Saúde [Internet]. [citado 29 out. 2021];21(44). Disponível em: https://www. revistas.unijui.edu.br/index.php/contextoesaude/article/view/11470

${ }^{21}$ Barros MMA, Cabral IE. Tendência dos estudos sobre poluição atmosférica e transtornos respiratórios na primeira infância, 1993-2019. Rev. Cont. Saúde [Internet]. [citado 29 out. 2021];21(44). Disponível em: https://www.revistas.unijui.edu.br/index.php/ contextoesaude/article/view/11240

22 Barros DSL, Otaviano Mesquita L, Rocha Santos T, Silva Lopes M, Michele Cassimiro da Silva Oliveira R, Ferreira Cavalcante C. Educação em saúde da atenção primária brasileira: uma pesquisa documental no contexto da pandemia da Covid-19. Rev. Cont. Saúde [Internet]. [citado 29 out. 2021];21(44). Disponível em: https://www.revistas.unijui. edu.br/index.php/contextoesaude/article/view/12256

${ }^{23}$ Félix TA, Oliveira EN, Lopes MV de O, Parente JRF, Dias MS de A, Moreira RMM. Fatores de risco para tentativa de suicídio: produção de conhecimento no Brasil. Rev. Cont. Saúde [Internet]. 22 dez. 2016 [citado 29 out. 2021];16(31):173-85. Disponível em: https://revistas.unijui.edu.br/index.php/contextoesaude/article/view/6079

${ }^{24}$ Menezes JNR, Monte Costa M de P, Silva Iwata AC do N, Mota de Araujo P, Oliveira LG, de Souza CGD, Duarte Fernandes PHP. A visão do idoso sobre o seu processo de enveIhecimento. Rev. Cont. Saúde [Internet]. 20 dez. 2018 [citado 29 out. 2021];18(35):812. Disponível em: https://revistas.unijui.edu.br/index.php/contextoesaude/article/ view/7620

${ }^{25}$ Antunes AS, Santos De Bona Libardoni K. Prevalência de enteroparasitoses em crianças de creches do município de Santo Ângelo, RS. Rev. Cont. Saúde [Internet]. 2 jun. 2017 [citado 29 out. 2021];17(32):144-56. Disponível em: https://revistas.unijui.edu.br/index.php/contextoesaude/article/view/6159

${ }^{26}$ Heck TG, Buratti GP, Kolankiewicz ACB. O que há de novo na Revista Contexto \& Saúde? Rev. Cont. Saúde [Internet]. 22 dez. 2016 [citado 30 nov. 2021];16(31):1-3. Disponível em: https://www.revistas.unijui.edu.br/index.php/contextoesaude/article/view/6559

27 Heck TG. O que há de novo no "novo" contexto da Revista Contexto \& Saúde? Rev. Cont. Saúde [Internet]. 17 ago. 2015 [citado 30 nov. 2021];15(28):1-2. Disponível em: https://www.revistas.unijui.edu.br/index.php/contextoesaude/article/view/4389 